\title{
OPTIMIZATION OF BACTERIAL CELLULOSE PRODUCTION FROM SUGAR BEET MOLASSES BY GLUCONACETOBACTER XYLINUS NRRL B-759 IN STATIC CULTURE
}

\author{
YUNUS EMRE ÖZ and MEHMET KALENDER \\ Department of Bioengineering, Firat University, 23100, Elazı̆g, Turkey \\ \Corresponding author: M. Kalender, mkalender@firat.edu.tr
}

Received June 16, 2021

We investigated the optimization of bacterial cellulose (BC) production from sugar beet molasses by Gluconacetobacter xylinus NRRL B-759 in static culture. The optimization studies were performed using the central composite design (CCD) of response surface methodology (RSM). The independent variables were the molasses concentration, inoculation ratio and culture volume. The dependent variable was BC production yield. From the optimization tests, based on the model developed by RSM-ANOVA, it was found that binary interactions between molasses concentration-culture volume and inoculation ratio-culture volume had the most significant influence on the responses. The optimum conditions were as follows: $78.932 \mathrm{~g} / \mathrm{L}$ molasses concentration, $12.973 \%$ inoculation ratio, and $130.405 \mathrm{~mL}$ of culture volume. The obtained BC was characterized by Fourier transform infrared spectroscopy (FTIR), scanning electron microscopy (SEM) and elemental analysis. The characterization results obtained in the study revealed that the produced BC exhibited typical FTIR spectrum, elemental composition, and nanofiber structure.

Keywords: bacterial cellulose, sugar beet molasses, Gluconacetobacter xylinus NRRL B-759, optimization, static culture

\section{INTRODUCTION}

Cellulose is the most abundant biomaterial in the world and is traditionally extracted from plants and their wastes. ${ }^{1,2}$ Its annual production amounts to approximately $10^{12}$ tons. ${ }^{3,4}$ According to a market research report, the cellulose fiber market was \$20.61 billion in 2015, and it is strongly expected to increase. ${ }^{5}$ Though cellulose is mainly extracted from wood pulp, other nonwood resources have also gained ground, such as cotton, algae, ramie, flax, hemp and bacterial cellulose (BC). ${ }^{4}$ This biomaterial and its derivatives (for example, cellulose esters and ethers) are used in many different industrial areas, such as in foods, textiles, paper, biomedical materials, pharmaceuticals, membranes, drilling, coatings, and building materials. ${ }^{2,6-8}$

To obtain cellulose from wood or other plants, it must be separated from lignin and hemicelluloses. For this, the raw material is subjected to different treatments, such as chemical, physico-chemical, enzymatic etc. ${ }^{9}$ However, these synthesis techniques for cellulose production have important disadvantages, for example, acid and alkali treatments used for lignin and hemicellulose removal may cause environmental pollution, the enzymatic route is expensive because of the high cost of enzymes; in addition to the deforestation problem when it comes to wood derived cellulose.

Biosynthesis is a route to produce cellulose using different types of microorganisms, such as algae, fungi and bacteria. ${ }^{9,10}$ The most commonly used bacteria in BC production are Acetobacter, Achromobacter, Aerobacter, Agrobacterium, Alcaligenes, Pseudomonas, Rhizobium, Sarcina, Zoogloea, Salmonella, Enterobacter, Escherichia, and some cyanobacteria. ${ }^{8,11,12}$ Nano-sized BC is generally synthesized using low-molecular-weight sugars and alcohols and its fiber diameter ranges from 20 to $100 \mathrm{~nm}^{6}{ }^{6}$ Although $\mathrm{BC}$ has the same chemical formula $\left(\mathrm{C}_{6} \mathrm{H}_{10} \mathrm{O}_{5}\right)$ as the cellulose originating from plants, some properties are different. As BC consists of only the glucose monomer, it has extra purity, nanostructure, high water holding capacity or hydrophilicity, high polymerization degree, high mechanical strength 
and high crystallinity., ${ }^{2,13}$ Due to these features, $\mathrm{BC}$ is recommended in many industrial applications, including biomedical products, foods, textiles and electronics. ${ }^{6,14,15}$

The most important parameters in BC production are the carbon and nitrogen sources used, as well as their ratio, the $\mathrm{pH}$, the volume of the culture medium, the inoculum ratio, incubation time and temperature.,16 The most often used carbon sources for BC production, as reported in the literature, are monosaccharides (various pentoses and hexoses), disaccharides, such as sucrose and mannose, and polysaccharides, such as dextran and starch; while yeast extract, peptone, casamino acids and corn steep liquor are the major nitrogen sources. ${ }^{17-21}$ Sugar beet molasses, a by-product of the sugar industry, were reported by Bae and Shoda ${ }^{22}$ to be used as a carbon source to produce BC.

$\mathrm{BC}$ can be produced by static, dynamic (or agitated/shaking), and bioreactor culture techniques. Although the static culture has the disadvantages of high cost and low rate of production, compared to the dynamic and bioreactor ones, it is a relatively simple technique. Furthermore, the BC produced by static culture has a more suitable particle size range and regularly shaped fibers than that produced by the dynamic and bioreactor culture techniques. ${ }^{23}$

This study aims to optimize some important process conditions of $\mathrm{BC}$ production from sugar beet molasses using G. xylinus NRRL B-759 in a static culture.

\section{EXPERIMENTAL}

\section{Materials and reagents}

The molasses used in this study were supplied by Elazığ Sugar Factory in Turkey. Some properties of the molasses samples are given in Table 1. Also, yeast extract (Chemsolute), peptone (Labm), acetic acid
(Merck), glycerol (Merck), sucrose (Carlo Erba), and fructose (Carlo Erba) were used. Other chemicals, such as glucose, citric acid, sodium hydroxide, and $\mathrm{Na}_{2} \mathrm{HPO}_{4}$, were of analytical grade.

\section{Bacterial strain and culture}

In this study, G. xylinus was used in the production of BC. The G. xylinus strain was obtained from ARS Culture Collection (NRRL B-759). This strain was cultured in Hestrin and Schramm (HS) ${ }^{24}$ medium, containing $2 \%$ glucose, $0.5 \%$ peptone, $0.5 \%$ yeast extract, $0.27 \% \quad \mathrm{Na}_{2} \mathrm{HPO}_{4}$ and $0.15 \%$ citric acid (the percentage values are in $\mathrm{w} / \mathrm{v}$ ratio). The $\mathrm{pH}$ was adjusted to 5, using $1 \mathrm{~N}$ acetic acid solution. The HS medium was sterilized by autoclaving at $121{ }^{\circ} \mathrm{C}$ for 15 minutes. The lyophilized G. xylinus strain was inoculated into $50 \mathrm{~mL}$ of sterile $\mathrm{HS}$ medium in a 250 $\mathrm{mL}$ flask and incubated at $30{ }^{\circ} \mathrm{C}$ for seven days. Cellulose production was observed at the end of the $7^{\text {th }}$ day. After cellulose production, a stock culture was prepared from the broth culture. An amount of $100 \mu 1$ of stock culture was transferred into an Eppendorf tube and $1000 \mu 1$ sterile glycerol solution (60\%) prepared with distilled water was slowly added to the tubes containing the stock culture. These stock cultures were maintained at $-80{ }^{\circ} \mathrm{C}$ until use in the fermentation experiments.

\section{Fermentation and optimization experiments}

The fermentation time of the strain $(G$. xylinus NRRL B-759) chosen in this study was used from our previous work ${ }^{25}$ related to the production of $\mathrm{BC}$ from molasses using different ethanol ratios. The fermentation time-determining experiments were performed with ten control sets in an incubator at 30 ${ }^{\circ} \mathrm{C}$ for a total of 20 days. The changes in the BC amount produced and glucose concentration in the culture media were measured over time. Both BC $(\mathrm{g} / \mathrm{L})$ and glucose concentration $(\mathrm{g} / \mathrm{L})$ proved to be independent of time after the tenth day. Thus, the fermentation experiments in the present study were conducted for 10 days.

Table 1

Composition of molasses samples in this study

\begin{tabular}{lc}
\hline Parameter & Value \\
\hline Total solid material content & $78.90 \%$ \\
Total sugar content & $50.80 \%$ \\
Total dissolved solid material content & $60.60 \%$ \\
pH & 8.10 \\
\hline
\end{tabular}

In order to optimize the batch fermentation conditions for BC production from sugar beet molasses, RSM based on the CCD was used. The RSM analyses were carried out using three independent variables: the molasses concentration $(40-236 \mathrm{~g} / \mathrm{L})$, the inoculation ratio $(5-15 \%)$, and the culture volume 
(100-250 mL). The ranges of the selected variables were determined by preliminary experiments based on a literature review. The codes and variation ranges of independent variables in the RSM-CCD for BC production from sugar beet molasses are given in Table 2. Table 3 tabulates the experimental conditions offered by the RSM-CCD according to these levels. The response variable was the $\mathrm{BC}$ production percent yield, defined as the ratio of produced $\mathrm{BC}$ mass $(\mathrm{g})$ to the initial sugar mass ( $g$ ) in the sugar beet molasses solution.
A typical fermentation experiment was as follows: any experimental condition in Table 3 was prepared using the related volumes in an autoclavable polypropylenebased culture vessel, with a volume of approximately $700 \mathrm{~mL}(95 \times 100 \times 74 \mathrm{~mm})$. This medium was autoclaved at $121{ }^{\circ} \mathrm{C}$ for 15 minutes, the G. xylinus NRRL B-759 strain was inoculated under aseptic conditions in a laminar air-flow cabinet, and the fermentation broth was kept in an incubator at $30{ }^{\circ} \mathrm{C}$ for 10 days.

Table 2

Symbols and levels of independent variables in central composite design (CCD) by response surface methodology (RSM) for bacterial cellulose (BC) production from sugar beet molasses

\begin{tabular}{ccccccc}
\hline Symbols & Variables & $-\alpha$ & -1 & 0 & +1 & $+\alpha$ \\
\hline A & Molasses concentration $(\mathrm{g} / \mathrm{L})$ & 39.00 & 78.93 & 137.5 & 196.06 & 236.00 \\
$\mathrm{~B}$ & Inoculation ratio & 5.00 & 7.03 & 10.00 & 12.97 & 15.00 \\
$\mathrm{C}$ & Culture volume $(\mathrm{mL})$ & 100.00 & 130.40 & 175.00 & 219.59 & 250.00 \\
\hline
\end{tabular}

Table 3

Experimental conditions proposed by central composite design (CCD) in response surface methodology (RSM) for bacterial cellulose (BC) production from sugar beet molasses

\begin{tabular}{cccc}
\hline $\begin{array}{c}\text { Sample } \\
\text { No }\end{array}$ & $\begin{array}{c}\text { Molasses concentration } \\
(\mathrm{g} / \mathrm{L})\end{array}$ & $\begin{array}{c}\text { Inoculation ratio } \\
(\%)\end{array}$ & $\begin{array}{c}\text { Culture volume } \\
(\mathrm{mL})\end{array}$ \\
\hline 1 & 79 & 7 & 130 \\
2 & 196 & 7 & 130 \\
3 & 79 & 13 & 130 \\
4 & 196 & 13 & 130 \\
5 & 79 & 7 & 220 \\
6 & 196 & 7 & 220 \\
7 & 79 & 13 & 220 \\
8 & 196 & 13 & 220 \\
9 & 39 & 10 & 175 \\
10 & 236 & 10 & 175 \\
11 & 138 & 5 & 175 \\
12 & 138 & 15 & 175 \\
13 & 138 & 10 & 100 \\
14 & 138 & 10 & 250 \\
15 & 138 & 10 & 175 \\
16 & 138 & 10 & 175 \\
17 & 138 & 10 & 175 \\
18 & 138 & 10 & 175 \\
19 & 138 & 10 & 175 \\
20 & 138 & 10 & 175 \\
\hline
\end{tabular}

The fermentation medium was adjusted to $\mathrm{pH} 5$ with $0.1 \mathrm{M}$ acetic acid solution. At the end of the fermentation time, the sugar concentration of the fermentation medium and the $\mathrm{BC}$ amount produced were measured.

\section{Preparation of BC}

After cultivation, the $\mathrm{BC}$ produced was separated from the culture medium and washed with distilled water. Then, it was subjected to centrifugation using a NUVE-NF $800 \mathrm{R}$ at $4100 \mathrm{rpm}$. In order to remove microbial product contaminants, the cellulose floccules produced were washed with $0.1 \mathrm{~N} \mathrm{NaOH}$ solution in a boiling bath $\left(60 \mathrm{~min}\right.$ at $\left.90{ }^{\circ} \mathrm{C}\right)$. After neutralization with $0.1 \mathrm{~N}$ acetic acid solution, the purified $\mathrm{BC}$ samples were washed with water and dried in an oven (Lab Companion $\mathrm{ON}-22$ ) at $70{ }^{\circ} \mathrm{C}$ until they reached a constant weight. $^{26}$

\section{Sugar analyses}

All sugar analyses were carried out using the HPLC technique in this study. For this purpose, the HPLC 
(Shimadzu LC-20) device with an RID detector was used. The column, analysis temperature, mobile phase, and flow rates were ICE-COREGEL-87H3, $45{ }^{\circ} \mathrm{C}$, $0.05 \mathrm{M} \mathrm{H}_{2} \mathrm{SO}_{4}$, and $0.6 \mathrm{~mL} / \mathrm{min}$, respectively.

\section{Characterization techniques}

Fourier-transform infrared (FTIR) spectroscopy of the BC samples produced under the optimum conditions was performed using an ATI Unicam Mattson 1000 device, with a resolution of $4 \mathrm{~cm}^{-1}$ in the wavenumber range from 4.000 to $400 \mathrm{~cm}^{-1}$.

The scanning electron microscopy (SEM) images of the BC samples were obtained using a JEOL JSM$7001 \mathrm{~F}$ device. The elemental analysis of the BC produced was performed using a LECO-CHNS-932 Elemental Analyzer.

FTIR, SEM and elemental analysis were carried out using samples produced under the optimum experimental conditions proposed by RSM.

\section{RESULTS AND DISCUSSION Optimization results}

The evolution of the $\mathrm{BC}$ yield $(\mathrm{g} / \mathrm{L})$ as a function of the fermentation time was described in our previous study. ${ }^{25}$ Here, the changes in the $\mathrm{BC}$ yield $(\mathrm{g} / \mathrm{L})$ are considered as a function of the $\mathrm{pH}$ during the fermentation time and the revised graph is illustrated in Figure 1. As may be noticed in Figure 1, the initial adjusted value of the fermentation medium of $\mathrm{pH} 5$ decreased to $\mathrm{pH} 4.3$ on the $10^{\text {th }}$ day. Similar $\mathrm{pH}$ changes were also found in other studies aiming to produce $\mathrm{BC}$ from molasses and HS medium with various $G$. xylinus strains. ${ }^{27}$ This decrease in the $\mathrm{pH}$ of the fermenting medium might be caused by gluconic acid, which is a by-product. ${ }^{27-30}$ It should be remarked that the decrease in $\mathrm{pH}$ during this time interval did not inhibit BC production. Also, sugar beet molasses contain a lower amount of glucose than the HS medium. This leads to less gluconic acid formation and, consequently, more $\mathrm{BC}$ production in this medium.

To optimize the experimental conditions (sugar beet molasses concentration, inoculation ratio and culture volume), RSM-CCD consisting of a set of 20 experiments, with six replicates at the central point, as given in Table 3, was conducted. The design results showed that the best fit model source was the quadratic model, among the linear, 2FI, and cubic model sources. The data obtained by the $\mathrm{P}$ test and Analysis of Variance (ANOVA) for the response surface carried out for the quadratic model suggested are given in Table 4.

As seen in the ANOVA results in Table 4, the quadratic model terms are significant due to probe $>\mathrm{F}$ value $(<0.0001)$ less than 0.05 . Thus, the significant model terms were $\mathrm{A}, \mathrm{B}, \mathrm{C}, \mathrm{AC}, \mathrm{BC}$, $A^{2}$, and $C^{2}$. Because the values of the model terms $\mathrm{AB}$ and $\mathrm{B}^{2}$ are greater than 0.1000 , these terms are not significant. According to the ANOVA test, some statistical parameters calculated from RSM$\mathrm{CCD}$ for $\mathrm{BC}$ production from sugar beet molasses are given in Table 5. Table 5 illustrates that the statistical parameter values of the quadratic model for the optimization of $\mathrm{BC}$ production in this study are very good. The standard deviation is low, while the $\mathrm{R}^{2}$ value is high. From the ANOVA tests carried out in this study, the lack of fit is not significant, which is a good result. In the RSM-ANOVA analyses, the Adeq Precision value is used to measure the signal/noise ratio.

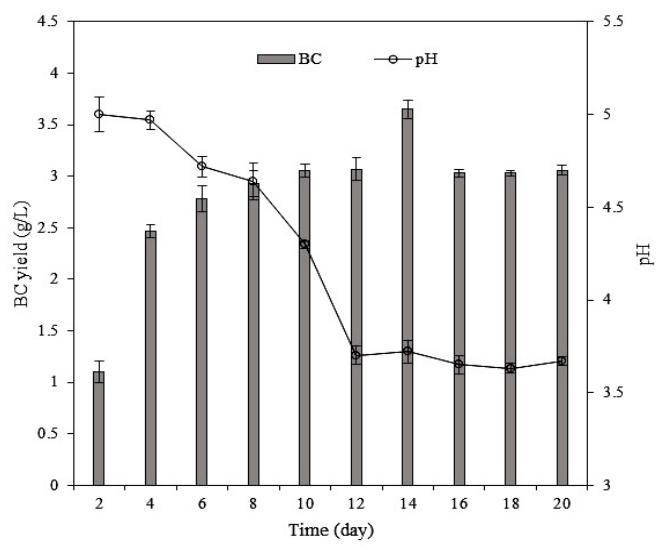

Figure 1: Bacterial cellulose (BC) production (bar chart) and $\mathrm{pH}$ change (line plot) of G. xylinus in HS medium at 30 
Bacterial cellulose

Table 4

Analysis of variance and P-test for bacterial cellulose (BC) production from sugar beet molasses

\begin{tabular}{lccccc}
\hline Source & $\begin{array}{c}\text { Sum of } \\
\text { squares }\end{array}$ & $\begin{array}{c}\text { Mean } \\
\text { square }\end{array}$ & F value & $\begin{array}{c}\text { p-value } \\
\text { Prob }>\text { F }\end{array}$ & \\
\hline Model & 78.890 & 10.700 & 76.160 & $<0.0001$ & Significant \\
A-Molasses concentration (g/L) & 33.160 & 33.160 & 236.020 & $<0.0001$ & \\
B-Inoculation ratio (\%) & 2.980 & 2.980 & 21.230 & 0.0006 & \\
C-Culture volume (mL) & 8.320 & 8.320 & 59.230 & $<0.0001$ & \\
AC & 5.760 & 5.760 & 41.020 & $<0.0001$ & \\
BC & 0.760 & 0.760 & 5.430 & 0.0381 & \\
A $^{2}$ & 12.550 & 12.550 & 89.130 & $<0.0001$ & \\
C $^{2}$ & 13.520 & 13.520 & 96.240 & $<0.0001$ & \\
\hline
\end{tabular}

Table 5

Statistical parameters calculated by response surface methodology (RSM) ANOVA for optimization of bacterial cellulose (BC) production

\begin{tabular}{lccc}
\hline Std. Dev. & 0.370 & $\mathrm{R}^{2}$ & 0.978 \\
Mean & 4.660 & Adj. $\mathrm{R}^{2}$ & 0.965 \\
C.V. \% & 8.050 & Pred. $\mathrm{R}^{2}$ & 0.910 \\
PRESS & 6.880 & Adeq. Precision & 25.448 \\
\hline
\end{tabular}

It is sufficient if the value is greater than 4 . From the ANOVA analysis, the ratio was calculated as 25.448. Thus, an adequate signal was obtained and the model can be used to navigate the design space. The difference between the Adj. $R^{2}(0.965)$ and Pred. $R^{2}(0.910)$ values is less than 0.2. This result indicates that the recommended model is in agreement with the experimental data. CV\% value, another ANOVA parameter, in Table 5 is 8.05. If the CV value of a model is less than $10 \%$, it is considered to be reproducible. ${ }^{31}$ Thus, the model is reproducible.

The expression of the final equation (except for the non-significant parameters in the model, i.e. $\mathrm{AB}$ and $\mathrm{B}^{2}$ ) in terms of actual factors generated by the design program is as follows:

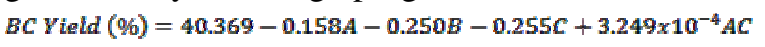

In this equation, the units of the model parameters used are $\mathrm{g} / \mathrm{L}$ for molasses concentration, volumetric percentage for inoculation ratio, and $\mathrm{mL}$ for culture volume.

To check the adequacy and reliability of the models obtained from the ANOVA test results, the residuals and the normal probability are commonly used. ${ }^{32}$ For this purpose, the predicted values versus the actual values, the externally studentized residuals versus the predicted BC production yield $(\%)$, the externally studentized residuals versus the run number, and the normal distribution probability charts of the studentized residuals were obtained, as illustrated in Figure 2 (a-d) for BC production from sugar beet molasses. As seen in Figure 2a, the experimental and predicted data points are close to the diagonal line. Figures $2 \mathrm{~b}$ and $2 \mathrm{c}$ show that there is a random distribution of points along the $\mathrm{x}$-axis between +3.894 and -3.894 . These graphs indicate that constant variance was observed through the response range. Due to the fact that the points on the normal distribution probability chart shown in Figure $2 \mathrm{~d}$ form a straight line and the errors in this graph were distributed normally, the model developed is sufficient.

The 3D and contour graphs of the molasses concentration-culture volume are shown in Figure 3 to account for binary interactions of the factors. The 3D response surface graph (Fig. 3a) shows that a minimum point surface chart was obtained. ${ }^{33}$ Therefore, the maximum BC production yield from sugar beet molasses can be obtained at minimum or maximum points. From Figure $3 \mathrm{a}$, it is understood that the effect of the molasses concentration on the $\mathrm{BC}$ production yield is higher than that of the culture volume. The $\mathrm{BC}$ yield had almost no change with varying culture volume at high molasses concentrations, but decreased with increasing culture volume at low molasses concentrations. 


\section{YUNUS EMRE ÖZ and MEHMET KALENDER}

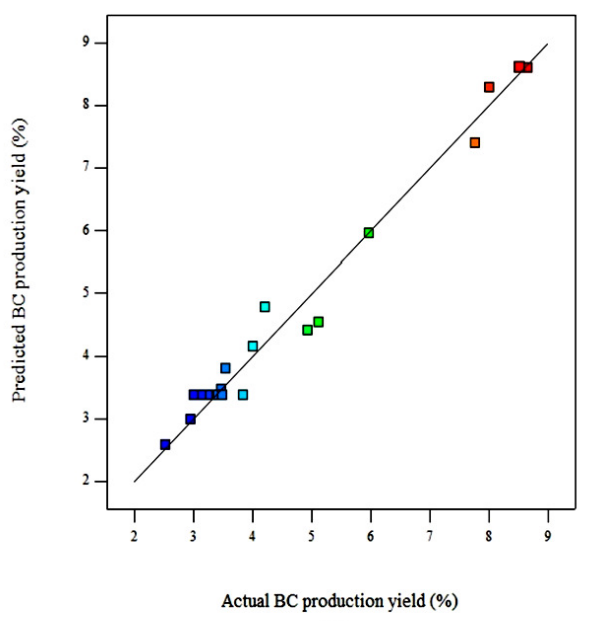

(a)

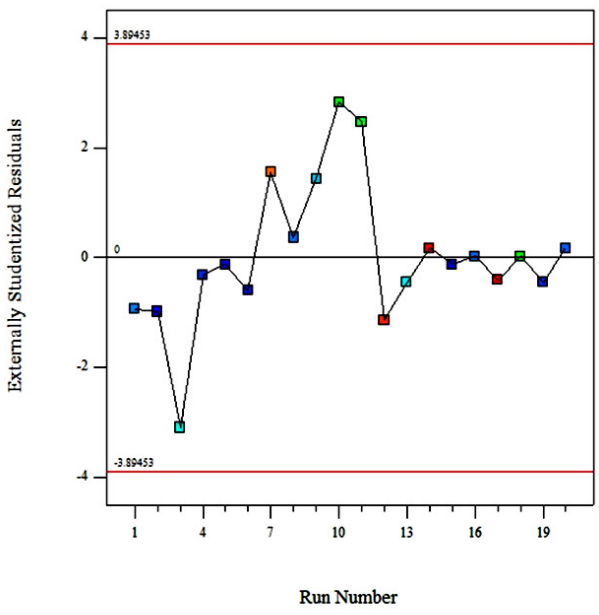

(c)

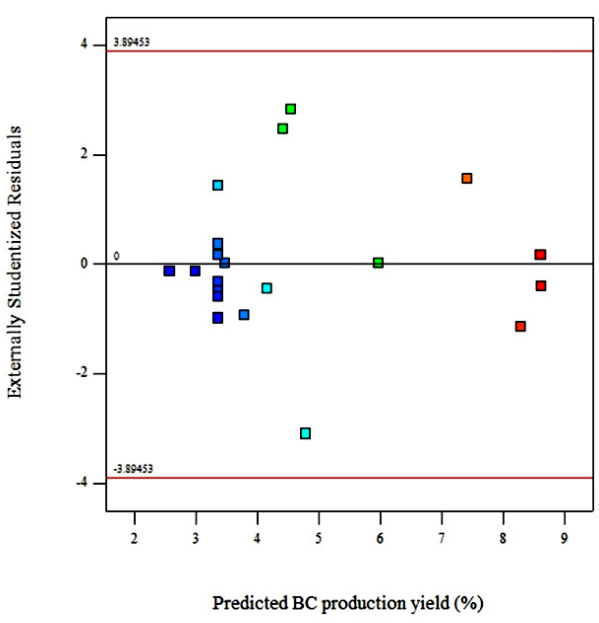

(b)

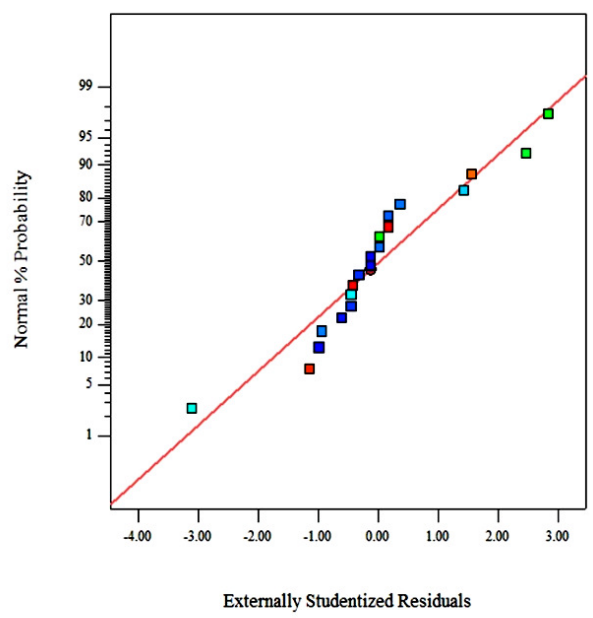

(d)

Figure 2: Graphs of experimental vs. predicted values (a), externally studentized residuals vs. predicted bacterial cellulose (BC) production yield (b), externally studentized residuals vs. run number (c), and normal plot of residuals (d) obtained by response surface methodology (RSM) analyses

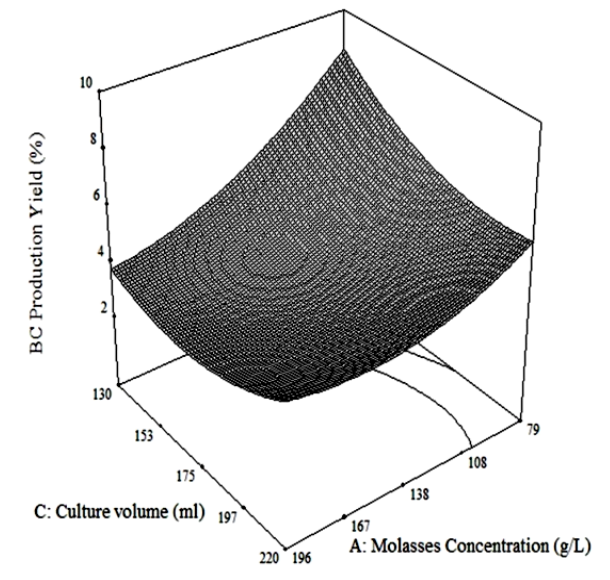



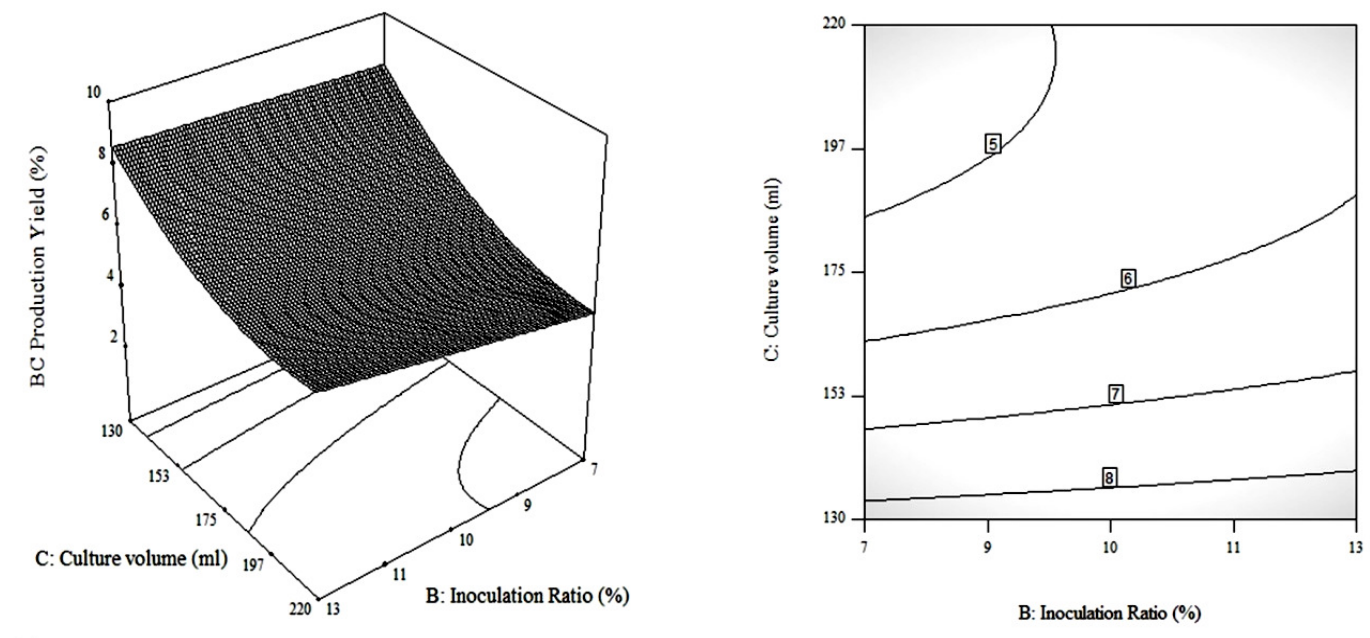

(a)

(b)

Figure 4: (a) 3D and (b) contour plots for B-C interaction (inoculation ratio-cumulative volume)

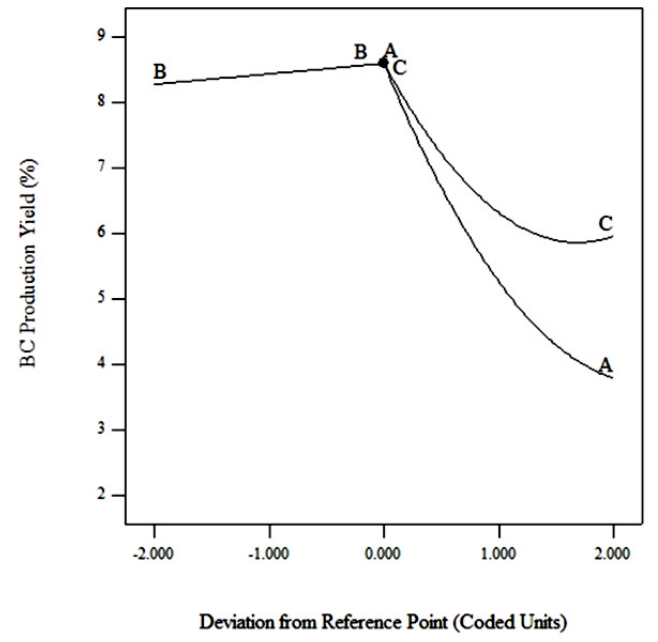

Figure 5: Perturbation graph obtained from response surface methodology (RSM) analyses for bacterial cellulose (BC) production yield from sugar beet molasses

Aytekin et $a l .^{34}$ also showed that BC production decreased with increasing culture volume ratio. Besides, the $\mathrm{BC}$ yield increased sharply with increasing molasses concentration in low culture volumes. However, the BC yield slightly increased with increasing molasses concentration in high culture volumes. The contour graph of molasses concentration-culture volume binary interaction given in Figure $3 b$ shows that the maximum $\mathrm{BC}$ production is observed at low concentrations and volumes for the examined experimental conditions. Figure 4 illustrates the 3D and contour plots of the inoculation ratio-culture volume binary interaction for $\mathrm{BC}$ production from sugar beet molasses. As seen in Figure 4a, the inoculation ratio did not significantly influence $B C$ production within the tested range. A similar result was also obtained in a previous paper $^{18}$ focused on $\mathrm{BC}$ production from maple syrup. It should be noted that, according to ANOVA results (Table 4), the inoculation ratio did not affect the BC production yield neither as the binary interaction of molasses concentrationinoculation ratio $(\mathrm{AB})$ nor as a quadratic $\left(\mathrm{B}^{2}\right)$. From Figure $4 \mathrm{a}$, the $\mathrm{BC}$ production yield decreased with increasing culture volume at both low and high inoculation ratio values. The contour chart shown in Figure $4 \mathrm{~b}$ illustrates that the culture volume must be at low values to achieve a high $\mathrm{BC}$ production yield.

The optimal points to obtain maximum $\mathrm{BC}$ production yield from sugar beet molasses used in this work proposed by RSM were $78.932 \mathrm{~g} / \mathrm{L}$ molasses concentration, $12.973 \%$ inoculation ratio, and $130.405 \mathrm{~mL}$ culture volume. The $\mathrm{BC}$ 
production yield \%, which is the response variable, was 8.604 , with 0.993 desirability under the optimum conditions.

In the RSM analyses, the perturbation plots can also be used to compare the effects of all the operating parameters investigated. A perturbation plot of the independent variables used in RSM analyses carried out in this work is presented in Figure 5. As seen in Figure 5, the response variable (BC yield) decreases with the increase in molasses concentration (A) and culture volume (C). However, the effect of inoculation ratio (B) on $\mathrm{BC}$ production is not significant. Thus, the molasses concentration and culture volume, individually, are more important parameters than the inoculation ratio in $\mathrm{BC}$ production from sugar beet molasses using G. xylinus NRRL B-759. This result is supported by the p-values in the ANOVA table (Table 4).

\section{Characterization results}

The $\mathrm{BC}$ pellicle produced in this study from sugar beet molasses using $G$. xylinus was approximately $95 \times 100 \mathrm{~mm}$ in size, with $66 \mu \mathrm{m}$ thickness.

The FTIR spectrum of the obtained BC sample is shown in Figure 6. Wang et al. ${ }^{35}$ stated that a pure cellulose sample exhibits wide absorption bands at $3350 \mathrm{~cm}^{-1}$, which are assigned to $\mathrm{O}-\mathrm{H}$ stretching vibrations. As seen in Figure 6, the BC produced here has an important peak in this wavelength range. The peak at $2900 \mathrm{~cm}^{-1}$ is attributed to the $\mathrm{C}-\mathrm{H}$ stretching vibrations of aliphatic hydrocarbons. ${ }^{35,36}$ Finally, the peaks at $1430 \mathrm{~cm}^{-1}, 1367 \mathrm{~cm}^{-1}$, and $1055 \mathrm{~cm}^{-1}$ correspond to $\mathrm{CH}_{2}$ symmetrical bending or surface carboxylate groups, $\mathrm{CH}_{2}$ wagging, ether $\mathrm{COC}$ functionalities and $\mathrm{C}-\mathrm{OH}$ stretching vibrations, respectively. ${ }^{37}$

A SEM image of the BC sample obtained under optimum conditions is illustrated in Figure 7. It reveals the nanofiber structure of the $\mathrm{BC}$, with randomly twisting ribbons. The heterogeneous appearance of the BC surface is due to the fibers alternating in bunches and forming clusters. The reason for forming fiber bunches and clusters is the tight entangling of the fibers due to intra- and inter-molecular hydrogen bonds. ${ }^{35}$ The size range of the $\mathrm{BC}$ fibers produced under the optimum conditions was from $33 \mathrm{~nm}$ to $100 \mathrm{~nm}$. This finding is in agreement with the results reported in previous studies. ${ }^{38,39}$

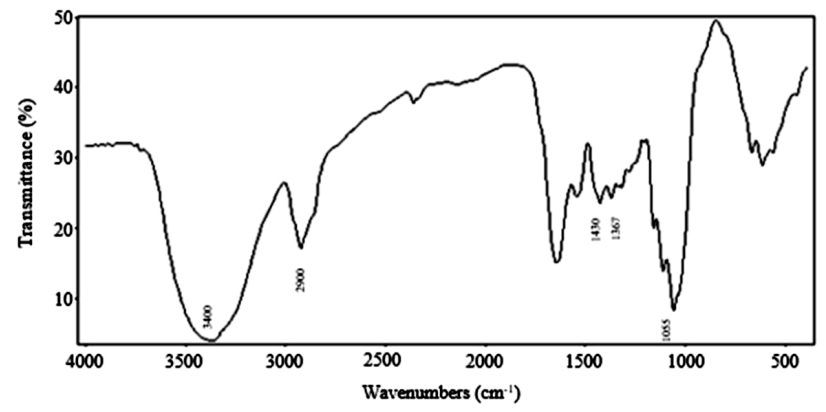

Figure 6: Fourier-transform infrared (FTIR) spectrum of bacterial cellulose (BC) produced from sugar beet molasses under optimum conditions

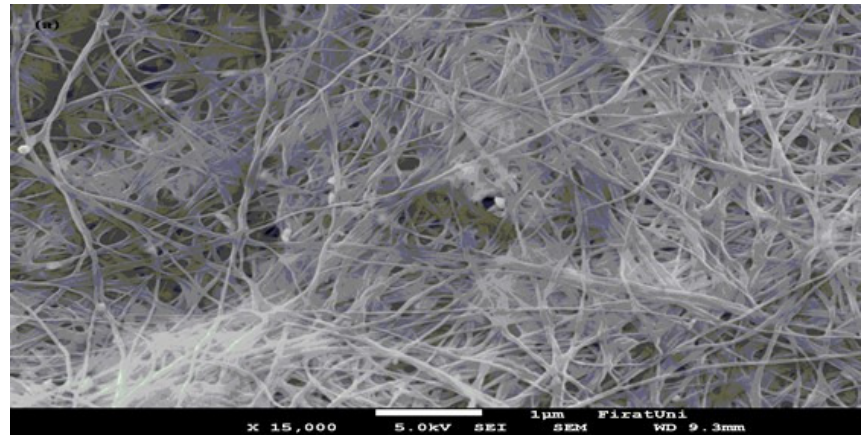

Figure 7: Scanning electron microscopy (SEM) image of bacterial cellulose (BC) produced from sugar beet molasses under optimum conditions 
The elemental analysis results showed that the $\mathrm{BC}$ sample contained $40.74 \% \mathrm{C}, 6.24 \% \mathrm{H}, 0.76 \% \mathrm{~N}$, and $0.11 \% \mathrm{~S}$. These elemental analysis results are similar to those determined for $\mathrm{BC}$ by Klem et $a .^{6}$

\section{CONCLUSION}

This study has presented the optimization of BC production from sugar beet molasses using $G$. xylinus NRRL B-759 in static culture. The data obtained by RSM-CCD methodology were then successfully employed in the experimental studies. The independent variables were molasses concentration, inoculation ratio, and culture volume, while the dependent variable was the $\mathrm{BC}$ production yield. As a result, the conclusions reached can be summarized as follows:

- The quadratic model was the best model among the models in the RSM-CCD;

- According to ANOVA, all model parameters, except $\mathrm{AB}$ and $\mathrm{B}^{2}$, were important;

- The statistical parameters, such as $\mathrm{R}^{2}$, Adj. $\mathrm{R}^{2}$, Pred. $\mathrm{R}^{2}$, lack of fit, Adeq. Precision, $\mathrm{SD}$, and $\mathrm{CV} \%$, were sufficient for the compatibility of the model;

- The effects of molasses concentrationculture volume and inoculation ratio-culture volume binary interactions on $\mathrm{BC}$ production were important;

- The inoculation ratio had a lower effect than the other model variables;

- The optimum conditions were found to be the following: $78.932 \mathrm{~g} / \mathrm{L}$ molasses concentration, $12.973 \%$ inoculation ratio, and $130.405 \mathrm{~mL}$ culture volume;

- FTIR results showed that the BC produced has a typical spectrum, compatible with literature data;

- $\quad$ SEM analysis indicated that the BC produced has nanofibers and a heterogeneous structure.

ACKNOWLEDGEMENTS: The authors wish to thank the FIRAT University Scientific Research Projects Unit for financial support (Project number: FÜBAP-MF.16.36).

\section{REFERENCES}

1 W. Czaja, D. Romanovicz and R. M. Brown, Cellulose, 11, 403 (2004), https://doi.org/10.1023/B:CELL.0000046412.11983.61 2 F. Esa, S. M. Tasirin and N. A. Rahman, Agric. Sci. $\begin{array}{llll}\text { Proc., } & \text { 2, } & 113 & \text { (2014), }\end{array}$ https://doi.org/10.1016/j.aaspro.2014.11.017
3 D. M. Nascimento, Y. L. Nunes, M. C. Figueirêdo, H. M. de Azeredo, F. A. Aouada et al., Green Chem., 20, 2428 (2018), https://doi.org/10.1039/C8GC00205C 4 D. Klemm, B. Heublein, H. P. Fink and A. Bohn, Angew. Chem. Int. Ed., 44, 3358 (2005), https://doi.org/10.1002/anie.200460587

5 Market Research Report, Cellulose Fiber Market Size, Share and Trends Analysis by Product Type (Natural, Synthetic), by Application (Textile, Hygiene, Industrial), by Regions and Segment Forecasts, 20182025, 2016, Access Date: 30.12.2019, https://www.grandviewresearch.com/industryanalysis/cellulose-fibers-market

6 D. Klemm, F. Kramer, S. Moritz, T. Lindström, M. Ankerfors et al., Angew. Chem. Int. Ed., 50, 5438 (2011), https://doi.org/10.1002/anie.201001273

H. Zhang, C. Chen, C. Zhu and D. Sun, Cellulose Chem. Technol., 50, $997 \quad$ (2016), https://www.cellulosechemtechnol.ro/pdf/CCT910(2016)/p.997-1003.pdf

8 R. Jonas and L. F. Farah, Polym. Degrad. Stab., 59, $101 \quad$ (1998), https://doi.org/10.1016/S01413910(97)00197-3

9 D. Klemm, D. Schumann, U. Udhardt and S. Marsch, Prog. Polym. Sci., 26, 1561 (2001), https://doi.org/10.1016/S0079-6700(01)00021-1

10 P. Carreira, J. A. Mendes, E. Trovatti, L. S. Serafim, C. S. Freire et al., Bioresour. Technol., 102, 7354

(2011), https://doi.org/10.1016/j.biortech.2011.04.081

11 C. Napoli, F. Dazzo and D. Hubbell, Appl. Environ. Microbiol., $\quad 30, \quad 123 \quad$ (1975), https://doi.org/10.1128/am.30.1.123-131.1975

12 B. S. Hungund and S. Gupta, World J. Microbiol. Biotechnol., 26, 1823 https://doi.org/10.1007/s11274-010-0363-1

13 M. Phisalaphong and N. Jatupaiboon, Carbohyd. Polym., $\quad 74, \quad 482 \quad$ (2008), https://doi.org/10.1016/j.carbpol.2008.04.004

14 M. Ul-Islam, M. W. Ullah, S. Khan and J. K. Park, Korean J. Chem. Eng., 37, 925 (2020), https://doi.org/10.1007/s11814-020-0524-3

15 M. Abba, Z. Ibrahim, C. S. Chong, N. A. Zawawi, M. R. A. Kadir et al., Fiber. Polym., 20, 2025 (2019), https://doi.org/10.1007/s12221-019-9076-8

16 E. Bilgi, E. Bayir, A. Sendemir-Urkmez and E. E. Hames, Int. J. Biol. Macromol., 90, 2 (2016), https://doi.org/10.1016/j.ijbiomac.2016.02.052

17 A. Kurosumi, C. Sasaki, Y. Yamashita and Y. Nakamura, Carbohyd. Polym., 76, 333 (2009), https://doi.org/10.1016/j.carbpol.2008.11.009

18 X. Zeng, D. P. Small and W. Wan, Carbohyd. $\begin{array}{llll}\text { Polym., } & \mathbf{8 5}, & 506 & \text { (2011), }\end{array}$ https://doi.org/10.1016/j.carbpol.2011.02.034

19 L. Chen, F. Hong, X.-X. Yang and S.-F. Han, Bioresour. Technol., 135, 464 (2013), https://doi.org/10.1016/j.biortech.2012.10.029 
20 Z. Li, L. Wang, J. Hua, S. Jia, J. Zhang et al., Carbohyd. Polym., 120, $115 \quad$ (2015), https://doi.org/10.1016/j.carbpol.2014.11.061

21 F. Mohammadkazemi, M. Azin and A. Ashori, Carbohyd. Polym., 117, $518 \quad$ (2015), https://doi.org/10.1016/j.carbpol.2014.10.008

22 S. Bae and M. Shoda, Biotechnol. Progr., 20, 1366 (2004), https://doi.org/10.1021/bp0498490

23 J. Wang, J. Tavakoli and Y. Tang, Carbohyd. Polym., 219, 63 (2019), https://doi.org/10.1016/j.carbpol.2019.05.008

24 S. Hestrin and M. Schramm, Biochem. J., 58, 345 (1954), https://doi.org/10.1042/bj0580345

25 Y. E. Öz and M. Kalender, Sci. Eng. J Firat Univ., 29, 31 (2017), https://dergipark.org.tr/tr/download/article-file/343473 26 M. Ishihara, M. Matsunaga, N. Hayashi and V. Tišler, Enzyme Microb. Technol., 31, 986 (2002), https://doi.org/10.1016/S0141-0229(02)00215-6

27 N. Tyagi and S. Suresh, J. Clean. Prod., 112, 71 (2016), https://doi.org/10.1016/j.jclepro.2015.07.054

28 M. Salari, M. S. Khiabani, R. R. Mokarram, B. Ghanbarzadeh and H. S. Kafil, Int. J. Biol. Macromol., 122, 280

(2019), https://doi.org/10.1016/j.ijbiomac.2018.10.136

29 C. Dirisu, J. Rosenzweig, E. Lambert and A. Oduah, J. Adv. Microbiol., 1 (2017), https://doi.org/10.9734/JAMB/2017/38440

30 B. Sun, Q. Zi, C. Chen, H. Zhang, Y. Gu et al., Cellulose Chem. Technol., 52, 795 (2018), https://www.cellulosechemtechnol.ro/pdf/CCT910(2018)/p.795-801.pdf

31 T. M. Alslaibi, I. Abustan, M. A. Ahmad and A. A. Foul, J. Environ. Chem. Eng., 1, 589 (2013), https://doi.org/10.1016/j.jece.2013.06.028
32 H. Pashaei, A. Ghaemi, M. Nasiri and B. Karami, ACS Omega, 5, $8432 \quad$ (2020), https://doi.org/10.1021/acsomega.9b03363

33 M. A. Bezerra, R. E. Santelli, E. P. Oliveira, L. S. Villar and L. A. Escaleira, Talanta, 76, 965 (2008), https://doi.org/10.1016/j.talanta.2008.05.019

34 A. Ö. Aytekin, D. D. Demirbağ and T. Bayrakdar, J. Ind. Eng. Chem., 37, 243 (2016), https://doi.org/10.1016/j.jiec.2016.03.030

${ }_{35}$ S. Wang, T. Huang, C. Lai, T. Xi, S. Liao et al., Cellulose Chem. Technol., 50, 853 (2016), https://www.cellulosechemtechnol.ro/pdf/CCT78(2016)/p.853-862.pdf

36 Y. Maréchal and H. Chanzy, J. Mol. Struct., 523, 183 (2000), https://doi.org/10.1016/S00222860(99)00389-0

37 F. Mohammadkazemi, K. Doosthoseini and M. Azin, Cellulose Chem. Technol., 49, 455 (2015), https://www.cellulosechemtechnol.ro/pdf/CCT56(2015)/p.455-462.pdf

${ }^{38}$ M. Abba, M. Abdullahi, M. H. Md Nor, C. S. Chong and Z. Ibrahim, IET Nanobiotechnol., 12, 52 (2018), https://doi.org/10.1049/iet-nbt.2017.0024

39 G. Gayathri and G. Srinikethan, Int. J. Biol. Macromol., $\quad$ 138, $950 \quad$ (2019), https://doi.org/10.1016/j.ijbiomac.2019.07.159 